\title{
COLOUR-GUIDELINES FOR THE UNIVERSITY OF MALAYA: FOCUSING ON UNIVERSITY IDENTITY
}

\author{
Yoosun Kim, Md Nasrudin Bin Md Akhir \& Yoomi Kim
}

\begin{abstract}
This study presents a suggested array of colour guidelines for the university homepage of the University of Malaya (UM) in Malaysia which represents the school's distinction and brand image. The importance of University Identity on institutional websites is to secure their identity and differentiation from other institutions. Despite having a multicultural heritage, it is difficult to find colour guidelines of any universities in Malaysia. There are limited studies on colour analysis of UM as one of the top public universities in Malaysia. We suggest colour guidelines using 18 types of primary colours, sub-colours, and second colour for the UM website that we believe would further reflect its University Identity, its status as well as enhance the nature of multicultural outlook of the institution. Accordingly, this study will have an academic and policy-level significance not only for Malaysia but other international institutions as well.
\end{abstract}

Keywords: University Identity, colour guidelines, University of Malaya, colours, design

\section{Introduction}

In an age of increasing and quickening competition, universities are entering a new phase in the world. In order to survive the competition, establishing a creative University Identity (UI) is becoming more important to secure the individuality of the university as well as to differentiate from other universities.1 The UI is defined as a design work for a university's image and it originated from a concept of corporate identity (CI) that is applied to universities. UI is used to build a university's image through all visual elements such as symbols, logos, colours, and fonts to boost brand value.2

UI helps to establish a successful university image by redefining a new symbol or image, therefore increasing the trust and belonging of its members internally and externally

\footnotetext{
$1 \mathrm{Yu}$, In-ha and Ji, Won-bae, 'An analysis on color and pattern of University's symbol mark design in terms of UI (University Identity) focusing on Universities in Seoul', Journal of Communication Design, 40, 2012.

2 Kwon, Yoon-Kyung, 'Correlation between slogan design and symbol mark of UI in University', Korean Contents Association, Vol. 13, No.8, 2013.
} 
while delivering a message that the university is constantly changing and developing. 3 Particularly, "colour" delivers a more direct and clearer message than other components as colour have an affect on the attitude of an observer. For example, from the perspective of marketers, management is needed through understanding of colours, from product packaging to CI.4 In so doing, UI can be an influential tool in enhancing a university's image.

Since the image of the university is reflected in human psychology through colours, the institution should build its own image through colours, which is one of the design elements in forming the university's own identity.5 This study is focused on an analysis on colours of the UI applied to a university's homepage. Since a university's website is the best method for public relations and advertising, it is necessary to carefully design the work to differentiate the university from other schools. 6 The importance of a university's UI on its website is steadily growing. Many universities present their own images by constructing web pages using certain colours to secure their identity and differentiation that contain their unique characteristics. However, the range of colours in institutional web pages reveals a lack of colour utilization in which only cast and auxiliary coloura are presented. In addition, there is a lack of colour harmony, the usage of various combinations, and utilization.7

Moreover, Malaysian cases are hard to find in the existing literature on designs and images; therefore, this study will have a positive effect on colour research in Malaysia. In the field of tourism, Malaysia is famous for the "colours of Malaysia." The "colours of Malaysia" signifies culture, fashion and traditional locations; it implies that Malaysia and colours are inextricably linked. However, it is difficult to find colour guidelines of public institutions in Malaysia. In particular, even though the University of Malaya (UM) is the best national

\footnotetext{
$3 \mathrm{Yu}$, In-ha and Ji, Won-bae, 'An analysis on color and pattern of University's Symbol mark design in terms of UI (University Identity) focusing on Universities in Seoul', Journal of Communication Design, 40, 2012; Lee, Ha-na, 'A study on logo design for enhancing competitiveness of college's brand focusing on color and pattern of University of Art and Design's logo affiliated in AICAD, USA', A Journal of Brand Design Association of Korea, Vol. 16, No.3, 2018.

4 Chun, Semi and Son, Won-jun, 2015, 'A study on Color identity for formation of company's image', Journal of Korea Design Forum, Vol. 47, 2015; Lee, Ha-na, 'A study on logo design for enhancing competitiveness of college's brand focusing on color and pattern of University of Art and Design's logo affiliated in AICAD, USA', A Journal of Brand Design Association of Korea, Vol. 16, No.3, 2018.

5 Son, Hye-yeon, 'A study on color design of sign and homage based on University's UI focusing on universities in Cheon-an', Journal of Korean Society of Colour Studies, Vol. 2, No. 3, 2009.

6 Jeong Jin-sook, 'A study on materialization of web identity for a design of University's website', Journal of Korea Design Forum, Vol. 12, 2005.

7 Lee, Ha-na, 'A study on logo design for enhancing competitiveness of college's brand focusing on color and pattern of University of Art and Design's logo affiliated in AICAD, USA', A Journal of Brand Design Association of Korea, Vol. 16, No.3, 2018.
} 
university in Malaysia and is ranked 38th among in Asia, a study about colour analysis on $\mathrm{UM}$ is rarely found in literature reviews. On the other hand, neighboring universities such as Nanyang Technology University (NTU) Singapore and the Ewha Woman's University in the Republic of Korea have published colour guidelines by analyzing their university logos or their UI along within their homepages. Hence, this study has an academic and policy-level significance for Malaysia. This study will suggest the colour guidelines that can be used on the website to improve the current study on colour utilization; it also suggests one indicator that can be applied to reflect the current trends. In addition, we will apply the university's represented colours to its website so that we can enhance the identity expression and originality of the university.

\section{Literature Review}

Amid rapidly changing trends, colour guidelines are mainly included in urban landscaping planning. Each city and county uses colours to provide uniqueness and differentiation of the region and as part of urban branding. Public administrations try to develop symbolic colours to build unique characteristics of their city, to symbolize the city and to strengthen its cultural identity; and establish practical guidelines that can be systematically applied to the functions and characteristics of the said city.8 Colour planning for overseas cities has taken place earlier than Malaysia's public institutions, and policies were established in various ways to establish their unique colour schemes.

\section{Seoul}

The city of Seoul developed its symbolic colours identifying it as a "city with a story of 600 years where tradition and modern characteristics coexisted." Colour guidelines were established by regions as part of an active strategy to establish the city's image. In order to discover and strengthen the cultural identity, the city published practical guidelines that could be systematically applied to Seoul's structural composition, characteristics, and 
commercialization.9 Through methodical research and analysis, Seoul's natural and human environmental colours were extracted into 250 phenomenological colours, 50 regional colours, and 10 representative colours.10 The colour scheme became a practical method for short and long-term urban planning by utilizing the extracted colours through the designation of the range of applications for each region and function (Figure 1).

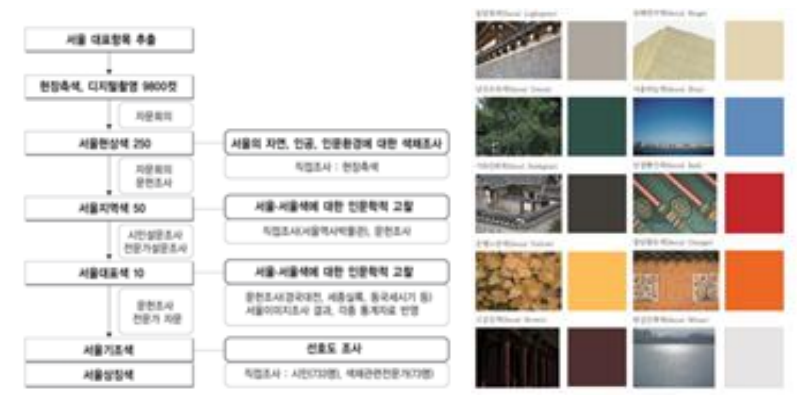

Figure 1. Colour guidelines development process of Seoul

\section{London}

In the early 1990's, the integration of signs and colours in various facilities in London, England was under the direction of the city's authorities. Manuals on the production, installation, size, and colour of various street facilities were then produced. Among them, signs indicating the name of subway stations with a blue background colour in the red circle pattern became regular since the 1990s. Additionally, in the case of a deteriorated facility, "black" or "blue" was added to the red background (Figure 2). Through the application of blue to the exterior of London City Hall, a new urban identity became transformed from red to blue.

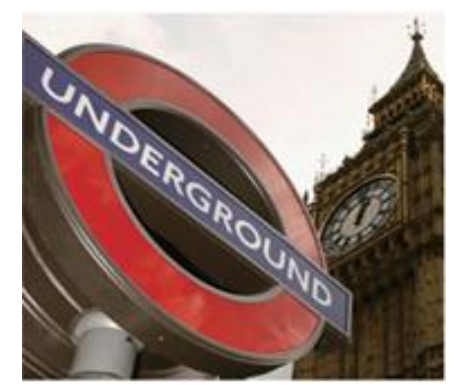

Figure 2. Facility design of London, England

9 Seoul Metropolitan Government, Introduction of Seoul's symbol-colour, http://www.seoul.go.kr/seoul/color.do?tr_code=short, accessed 26 Feb 2020.

10 Kim, Hyun-Sun, 'A Study on extraction local character from Seoul', Korea Society of Colour Studies, Vol.24, No 4, 2010. 


\section{Shimane Prefecture (島根県)}

In contrast, Shimane Prefecture of Japan produced colour guidelines using the four seasons and climate of the region (Figure 3). The guidelines are widely used for establishing colour landscape plans as well as in the use of environmental colours and colour extraction methods.
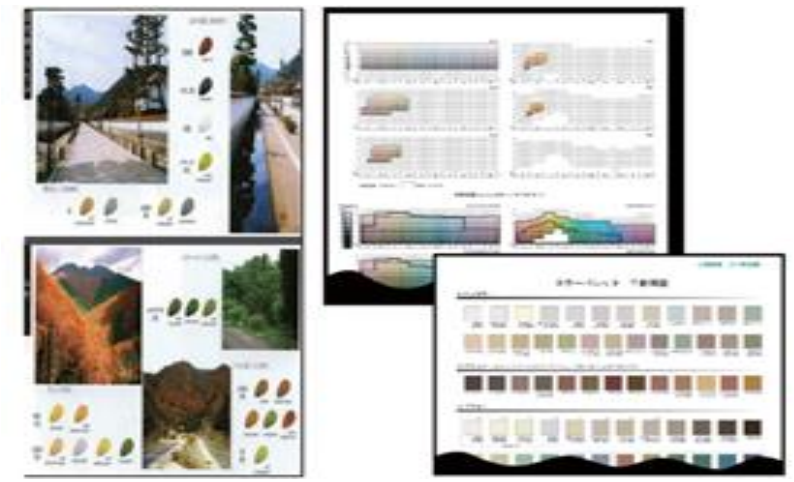

Figure 3. Colour guidelines of Shimane Prefecture

\section{Universities Abroad}

Presently, following the trend of globalization, many universities around the world have been working on branding and highlighting their unique identities. An in-depth explanation of the colours -including the university's represented colours- is shown below in Figure 4. It also includes the digital value standardization of colours as well as recommended ranges of dominant and assorted colours.
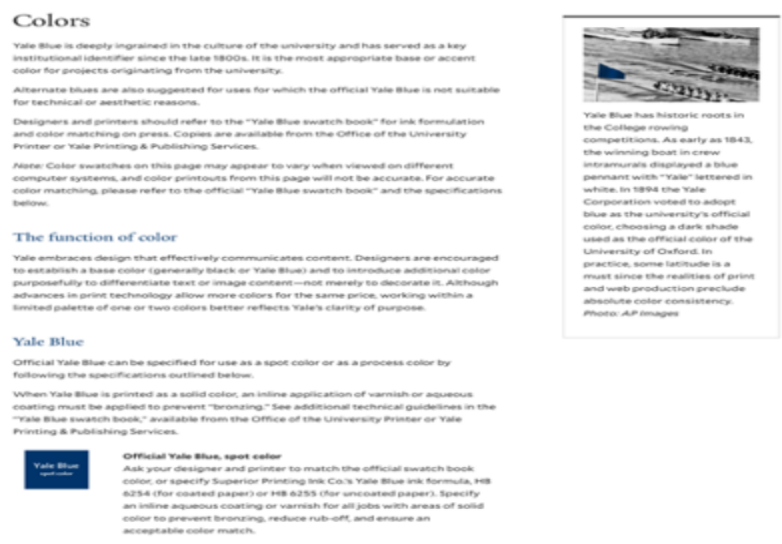

Figure 4. Colour guidelines of Konkuk University 11

11 Konkuk University website, KU UI,

https://www.kku.ac.kr/mbshome/mbs/wwwkr/subview.do?id=wwwkr_010406000000, accessed at 6 August 
It can be said that many universities in Korea have established their represented colours to express their image of the university through UI, and have presented colour guidelines using selected representative colours through effective standardization. However, in many cases, as shown in Figure 2, only the digital value standardization of colours are used. As shown in Figure 3, guidelines for using colours are also limited, and alternatives for applying them in various fields are not shown. In the case of Seoul Women's University (SWU), the institution established its colour guidelines (Figure 3) through three dominant and four assorted colours (Figure 6).

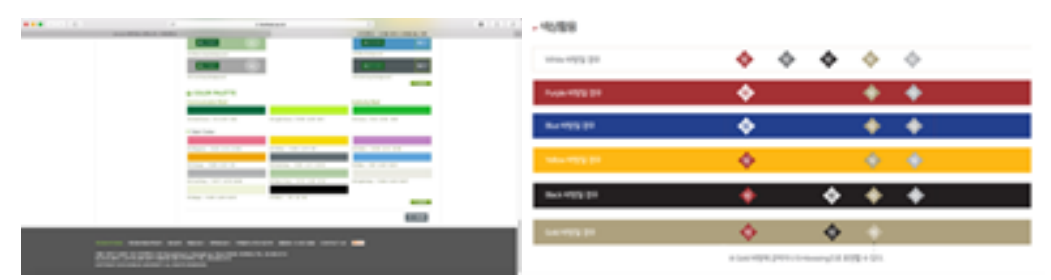

Figure 5. Colour guideline of Seoul Woman's University (SWU)

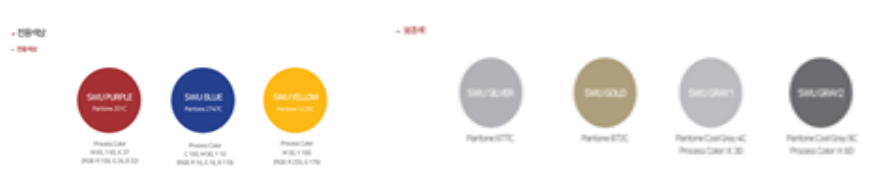

Figure 6. Colour palette of Seoul Women's University12

In contrast, Yale University, a prestigious American university that is anchored by its 300-year-old traditions and solid philosophy of education, its guidelines presents its history and usage of university-specific colours, the function of colours, and additional dominant colours. For example, Yale Blue represents Yale's exclusive colour which is blue; and its additional exclusive colour is also basically blue though it differs in saturation and brightness (Figure 7). Yale's colour palette consists of exclusive colours of the blue series, the auxiliary colours of gray series, and the accent colours of green and orange series (Figure 8).

2019.

12 Seoul Woman's University, UI, https://www.swu.ac.kr/www/symb_4.html, accessed at 2 August 2019. 


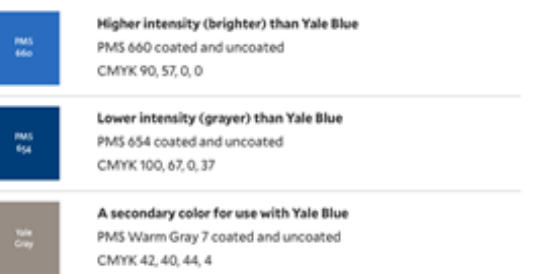

Figure 7. Yale University's additional standard colours

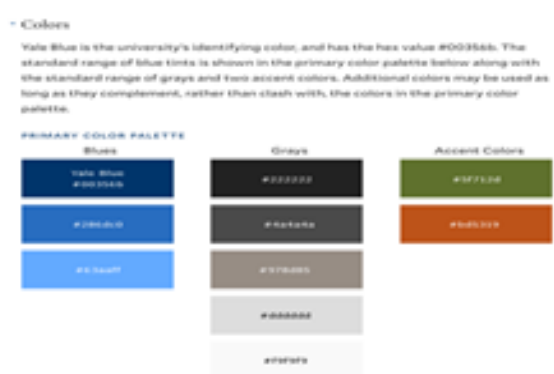

Figure 8. Colour palette for the Yale University website13

In the case of the Nanyang Technology University (NTU) which is a prominent university in Singapore known for its technological innovations and signature art and design programs, the university's colour guidelines corresponds with its UI within the category of brand guide. NTU classifies its colour guidelines into primary, secondary, and a prestige metallic colour palette. The palette is expressed in cyan, magenta, yellow, and black (CMYK); red, green, and blue (RGB); hexadecimal (HEX); and Pantone Colours, making it easy to understand the university's brand and image (Figure 9).14

SUB-BRAND LOGO

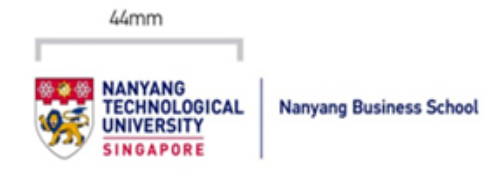

The sub-brand entity must appear with the master logo and the NTU logo needs to be minimally $44 \mathrm{~mm}$ in width in the sub-brand lockup. No party should attempt to create a sub-brand lockup.

\section{PRIMARY COLOURS}

CMYK 0.100 .70 .10 SPOT PANTONE (PMS) 200 RGB $\quad 215.20 .64$ HEX \#D71440 NTU Red and Blue

to be used predominantly on any marketing collateral

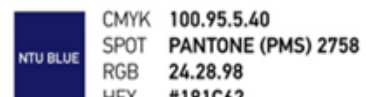

RGB $\quad 24.28 .98$

13 Yale University website, Yale Identity, https://yaleidentity.yale.edu/web, accessed at 27 November 2019. 14 A collection of colours produced by Pantone in USA. The number of colours is 1015 colours of glossy plate and 1013 of matte plate. 


\section{SECONDARY COLOURS}

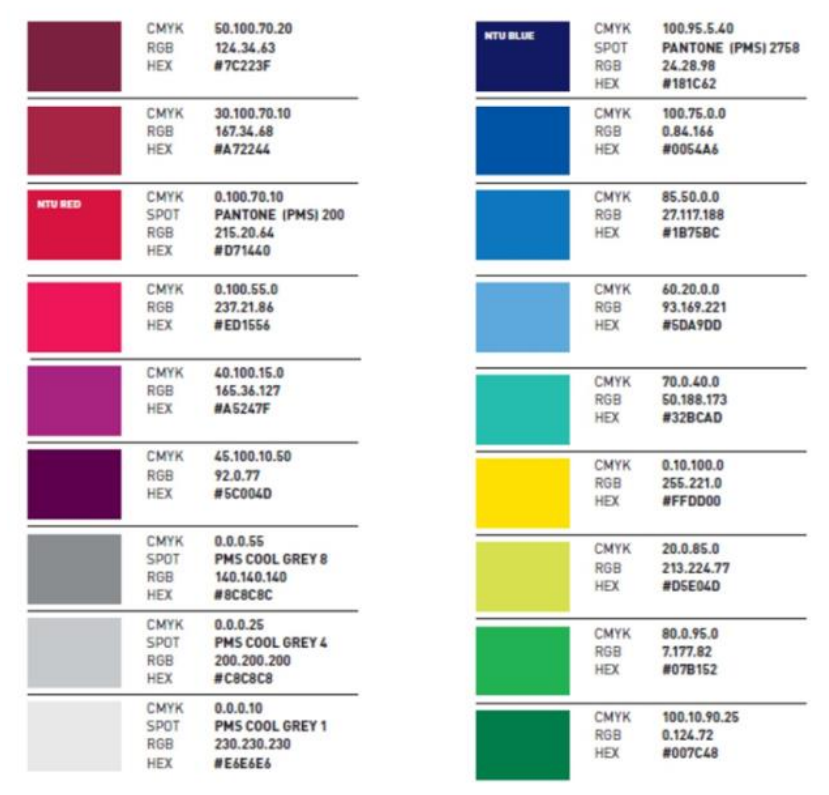

PRESTIGE METALLIC PALETTE
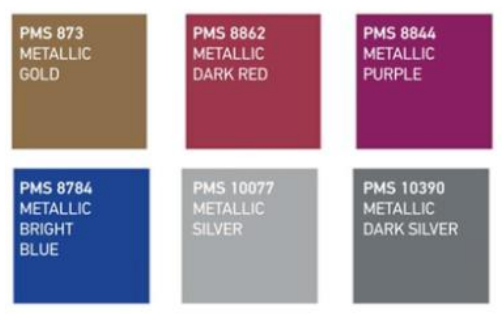

Figure 9. Colour palette for Nanyang Technology University (NTU)15

\section{Theoretical framework}

Colour harmonization has an association effect on multiple colours, and it provides value like beauty or comfort by using colours with the same, similar, or contrasting order.16 By harmonizing with combinations of colours with differences in brightness, combinations of colours and complementary colours that are close or far from the colour wheel, colour palette can become reminiscent of continuity, unity, and symbolism. Therefore, colours can be used for branding and marketing and by using the appropriate colour matching methods, it

15 NTU Singapore Quick Brand Guide, 2018,

https://www3.ntu.edu.sg/CorpComms2/NTU\%20Quick\%20Brand\%20Guide\%202018.pdf, accessed at 1 December 2019.

16 Kim Min-ki, Kim Yu-sun, Lee Ki-young, The official guide for Industrial engineers of Colourists, Seoul: Mijinsa, 2018. 
is possible to design competitive CI as well as UI.17 In this point of view, CI and UI should be visible and understandable from the viewer's perspective, which is comparable to the purpose of "universal design." The term universal design was first introduced by an American architect by the name of Ronald L. Mace under the philosophy of "design for all ages and abilities."18 This design philosophy is closely associated with the theory of colours for ease of use which advocates design for all. The colours that enter should be visible light for the eye and should be recognized by the brain. Colour universal design enhances products, facilities, buildings, environment, services, and information that are related to the diversity of human beings and are usually user friendly. Web pages of institutions are virtual spaces-not physical spaces - and can be configured in various ways depending on the purpose of the production. The pagescontains visual information, and it is a space where various design principles are added to induce the user's convenience through UI and User Experience (UX) designed into the web page. It is also the most effective and inexpensive medium to promote the brand by taking advantage of the fact that it is easily accessible to viewers. 19

Moreover, colour guidelines are used to give each university its uniqueness as part of branding. This involves the development of symbolic colours to build unique characteristics of a university as well as the establishment of colours to symbolize a university in order to discover and strengthen its cultural identity. In addition, colour guidelines establish practical guidelines that can be systematically applied to the characteristics of the universities.20

\section{Methodology}

The purpose of this study is to identify the colour guidelines for university websites. The subject of the research is UM, and the scope of the survey and analysis is associated with the physical image of exclusive colours and natural environments currently applied by the said

17 Bae, uri, "A Study on coloration of brand logo design focusing on Top 100 of most valuable global brands in 2015”, Milward Brown, in unpublished Ph.D.dissertation, Hongik University, 2016; Lee, Ha-na, 'A study on logo design for enhancing competitiveness of college's brand focusing on colour and pattern of University of Art and Design's logo affiliated in AICAD, USA', A Journal of Brand Design Association of Korea, Vol. 16, No. $3,2018$.

18 Joy E. Weeber, Ronald L. Mace, https://www.britannica.com/biography/Ronald-L-Mace, date unavailable, accessed at 1 December 2019.

19 Jeong Jin-sook, 'A study on materialization of web identity for a design of University's website', Journal of Korea Design Forum, Vol. 12, 2005; Son, Hye-yeon, 'A study on colour design of sign and homage based on University's UI focusing on universities in Cheon-an', Journal of Korean Society of Colour Studies, Vol. 2, No. 3, 2009.

20 Kim, Hyun-Sun, 'A Study on extraction local character from Seoul', Korea Society of Colour Studies, Vol. 24, Bo.4, 2010. 
institution. The study includes analyzing the elements of human environment of images, education, teaching, and lessons, so that a colour palette applicable to the university's homepage could be proposed. As a specific method, we examined intrinsic colours by utilizing information from literature reviews and case studies on UM. In order to construct colour guidelines for university webpages based on the literature review, visual inspections and existing digital mosaic methods using the Eyedropper tool from Adobe Illustrator were used to extract colour. UM's private colours were extracted using the Eyedropper tool, and its natural colours were extracted with a Canon EOS M3 mirrorless camera under natural daylight conditions between three hours after sunrise and three hours before sunset. Furthermore, a digital mosaic method using Eyedropper tool was also employed during this process. In order to understand not only physical factors such as natural environment and image of the target university, but also humanistic factors such as education, teaching, and lessons, we analyzed questionnaire about image colour through the SPSS Statistics software.

The UM Human Environmental Colours Survey was analyzed using 'Naver Office Form' and 'Microsoft Excel'. The colour expressions according to the analysis results were based on the KS(Korea Standard) colours system. For the printing and computer screens, the colour proposal was expressed in CMYK and RGB. In addition, the three main colours of the institution are also represented as Pantone colours.

\section{Findings}

UM's main colours have been analyzed as follows

Table 1. UM's main colours

\begin{tabular}{|l|l|l|}
\hline Colour & Colour chips & Value of colour \\
\hline MALAYA Blue & & C:94 M: $96: 6$ K: 0 (PANTONE 2736C) \\
\hline MALAYA Yellow & & C:6 M: 15 Y: 88 K:0 (PANTONE Medium Yellow) \\
\hline MALAYA Red & & C:6 M: 96 Y: 88 K:0 (PANTONE 2035C) \\
\hline
\end{tabular}




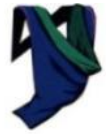

Academy of Islamic Studies

Malaya Green

$C: 88 \mathrm{M}: 41 \mathrm{Y}: 77 \mathrm{~K}: 45$

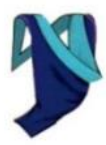

Faculty of Language \& Linguistics

Malaya Turguoise

C: $67 \mathrm{M}: 10 \mathrm{Y}: 26 \mathrm{~K}: 0$

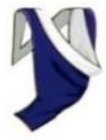

Faculty of Education

Malaya White

$C: 2 \mathrm{M}: \mathrm{OY}: 1 \mathrm{~K}: 0$

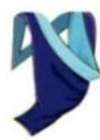

Faculty of Education

Malaya Cotton Candy Blue

$C: 45 \mathrm{M}: 0 \mathrm{Y}: 14 \mathrm{~K}: 0$

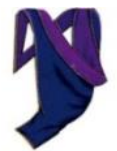

Faculty of Computer Engeneering \& Information Technology

Malaya Violet

C: $81 \mathrm{M}: 100 \mathrm{Y}: 14 \mathrm{~K}: 4$

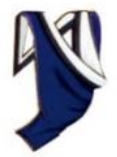

Asia-Europe Institute

Malaya Dalmatian

C: $0 \mathrm{M}: 2 \mathrm{Y}: 0 \mathrm{~K}: 0$

$\mathrm{C}: 100 \mathrm{M}: 100 \mathrm{Y}: 100 \mathrm{~K}: 100$

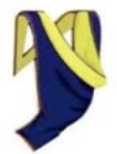

Sports Centre

Malaya Lemon Yellow

C: $11 \mathrm{M}: 2 \mathrm{Y}: 70 \mathrm{~K}: 0$

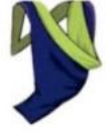

Academy of Malay Studies

Malaya Lemon Green

C: $39 \mathrm{M}: 7 \mathrm{Y}: 78 \mathrm{~K}: 0$

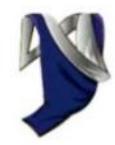

Faculty of Economics \& Administration

Malaya Silver

C : $43 \mathrm{M}: 29 \mathrm{Y}: 37 \mathrm{~K}: 10$

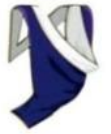

Institute of Educational Leadership

\section{Malaya Snow Flake}

$C: 4 \mathrm{M}: 3 \mathrm{Y}: 3 \mathrm{~K}: 0$

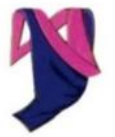

Faculty of Medicine

Malaya Crimson

$\mathrm{C}: 30 \mathrm{M}: 91 \mathrm{Y}: 22 \mathrm{~K}: 8$

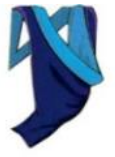

Faculty of Law

\section{Malaya Cloud Blue}

C: $74 \mathrm{M}: 20 \mathrm{Y}: 0 \mathrm{~K}: 0$

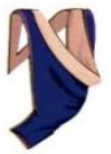

Institute of Graduate Studies

Malaya Peach

C: $7 \mathrm{M}: 25 \mathrm{Y}: 33 \mathrm{~K}: 0$

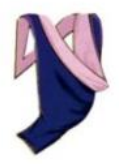

Faculty of Art \& Social Science

Malaya Cherry Blossom

C: $5 \mathrm{M}: 34 \mathrm{Y}: 4 \mathrm{~K}: 0$
Faculty of Built Environment

Malaya Emerald Green

C: $71 \mathrm{M}: 29 \mathrm{Y}: 43 \mathrm{~K}: 12$

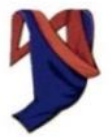

Faculty of Engeneering

Malaya Deep Orange

C : $23 \mathrm{M}: 85 \mathrm{Y}: 78 \mathrm{~K}: 16$

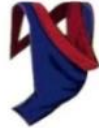

Faculty of Dentistry

Malaya Scarlet

C: $26 \mathrm{M}: 96 \mathrm{Y}: 28 \mathrm{~K}: 24$

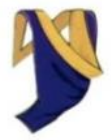

Faculty of Science

Malaya Gold

$C: 13 \mathrm{M}: 30 \mathrm{Y}: 73 \mathrm{~K}: 3$

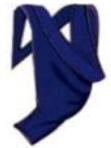

International Institute of Public Policy \& Mamagemet

Malaya Emerald Green

C: $71 \mathrm{M}: 29 \mathrm{Y}: 43 \mathrm{~K}: 12$

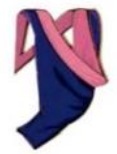

Cultural Centre

Malaya Coral Pink

$C: 2 \mathrm{M}: 63 \mathrm{Y}: 17 \mathrm{~K}: 0$

Figure 10. Colours of graduation gowns by academic institution and faculty at UM 
Simultaneously, the colours pertaining to UM's natural environment was extracted through Munsell colourization for the representative buildings and targeted places in campus. Table 2 shows a serial colouration belt.

Table 2. Extracted colours of UM's natural environment

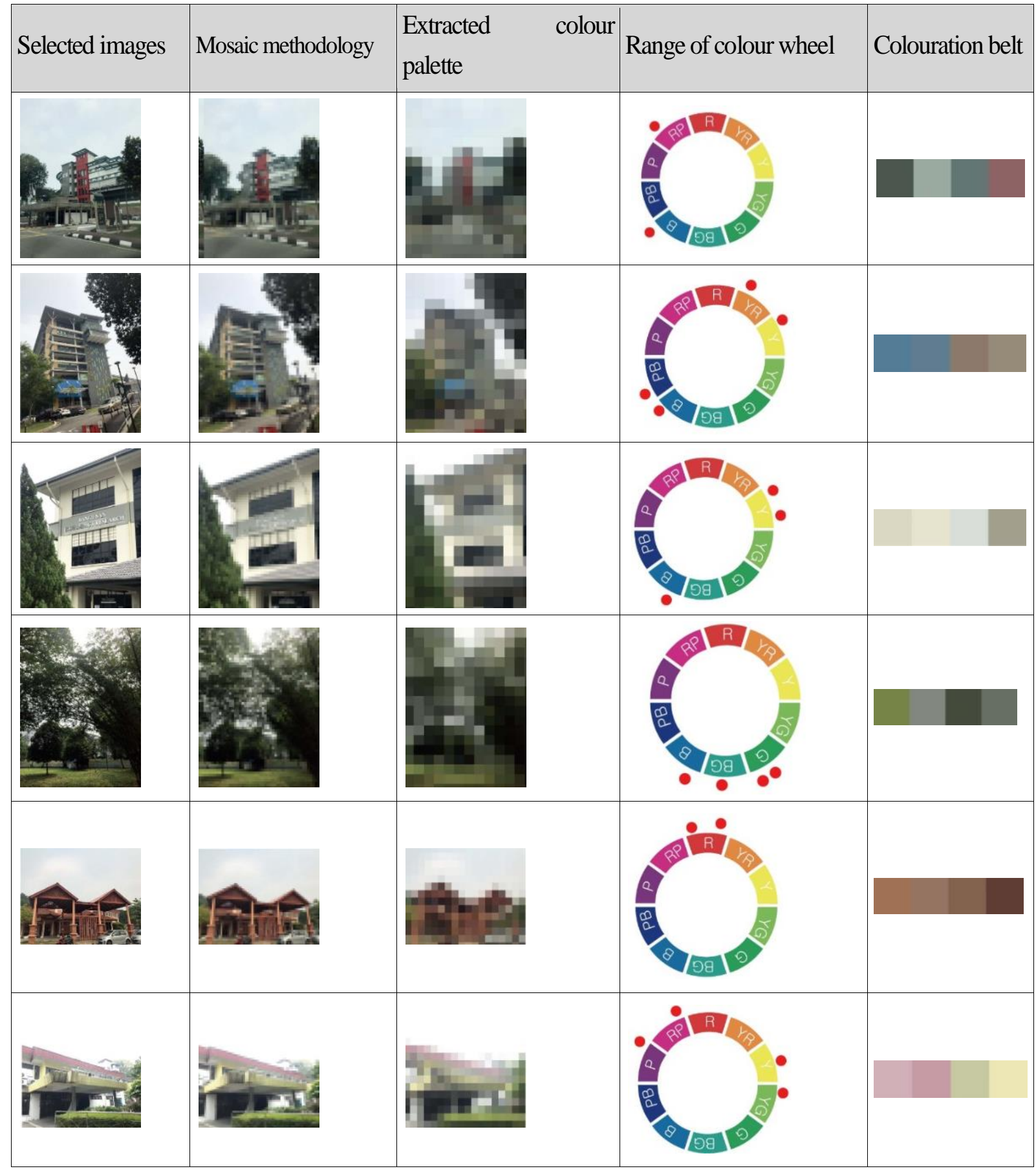


In terms of human environmental factors, we examined colours and tones associated with images of UM through a survey. $26 \%$ participants were men and $74 \%$ were women who attended the university (Figure 11).

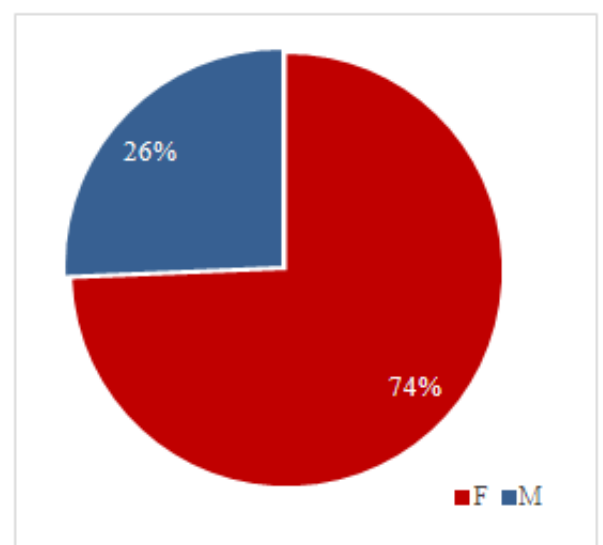

Figure 11. Percentages of participants by gender

Using the I.R.I image scale, we analyzed the result of the questionnaire related to images associated with UM.21 Participants reflected pride in the images of UM whereby 52\% signified them as "Top/Best." Subsequently, the rest viewed the same images to be "Old," "Famous," "Classic," Academic and so on between $4 \%$ and 10\% (Figure 12).

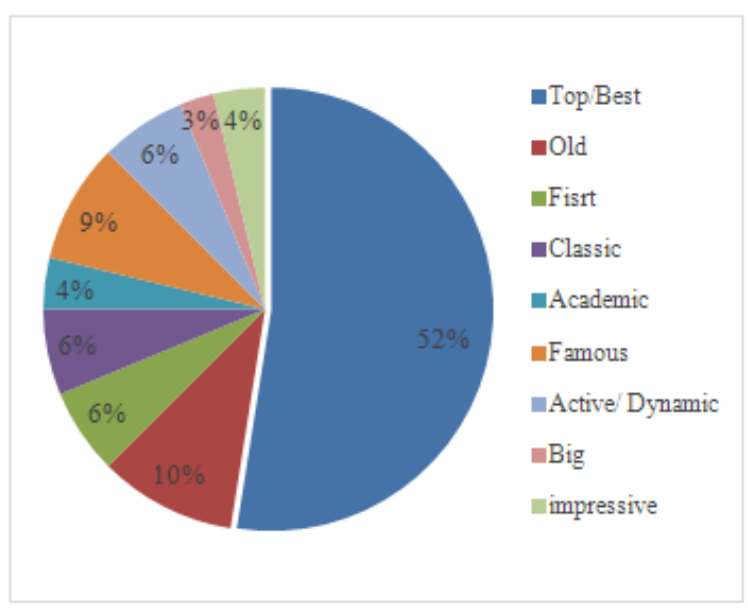

Figure 12. Respondents on UM's image

21 Park Yeon-sun, A dictionary for terms in fields of colour design, Seoul: Yeorim, 2007. 

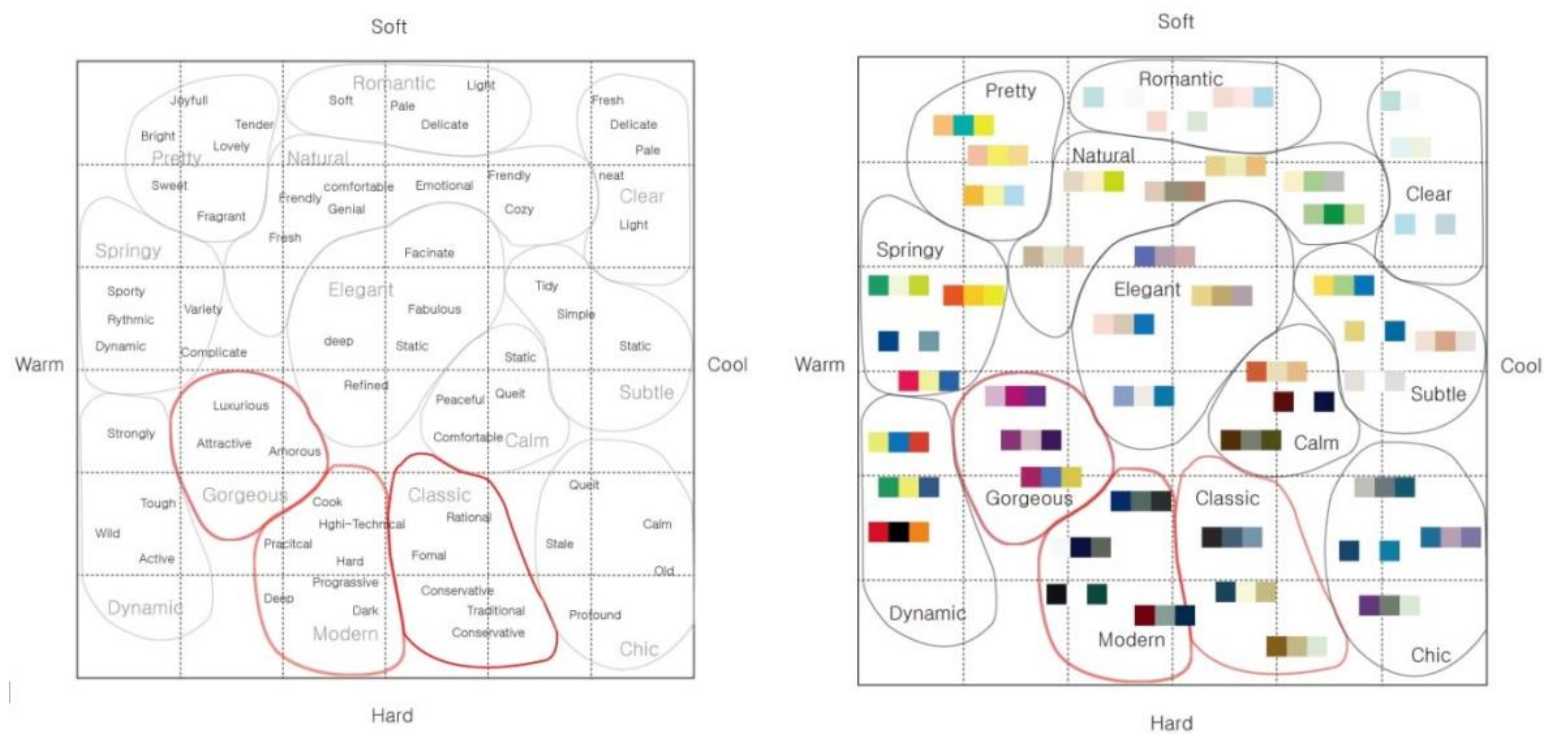

Figure 13. IRI image scale on UM's image

When analyzed using I.R.I image scale, images of the university generated characteristics such as gorgeousness, classic themes, calmness, and modernity (Figure 13). As a result of examining the colours and tones perceived in images of the university, as shown in Figure 14, overwhelmingly $66 \%$ of the colour images were dominated by blue colour. This was followed by yellow (12\%), red purple (9\%) and purple blue (7\%). Figure 15 indicates two strongest clear-toned images. The highest was a vivid tone which was at 33\% and a darker one at $22 \%$.

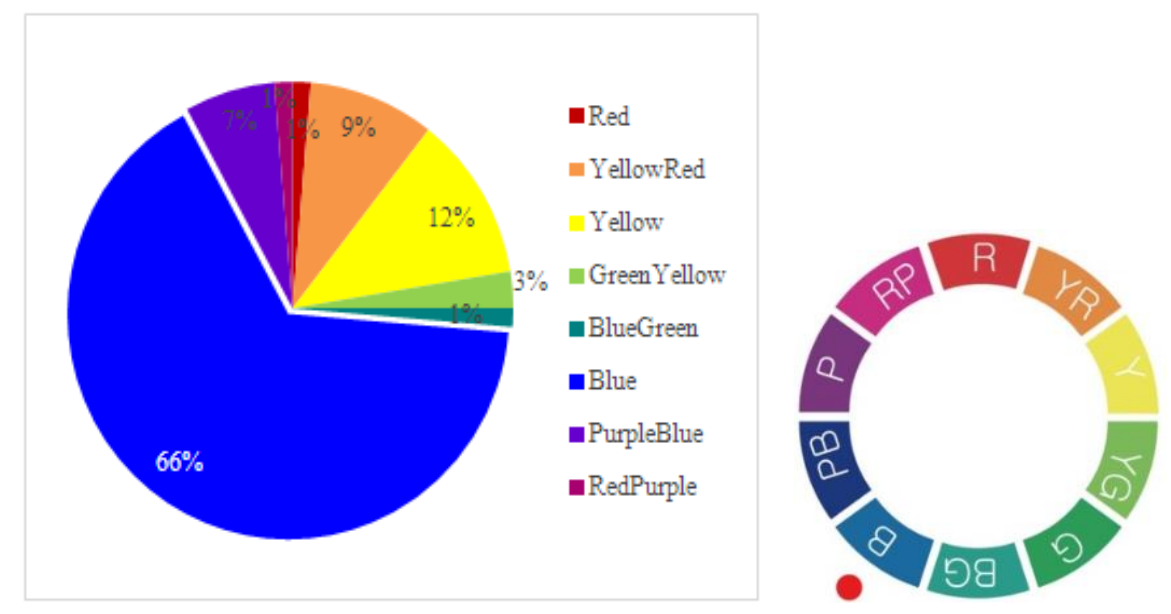

Figure 14. The result of survey on colour of image at UM 

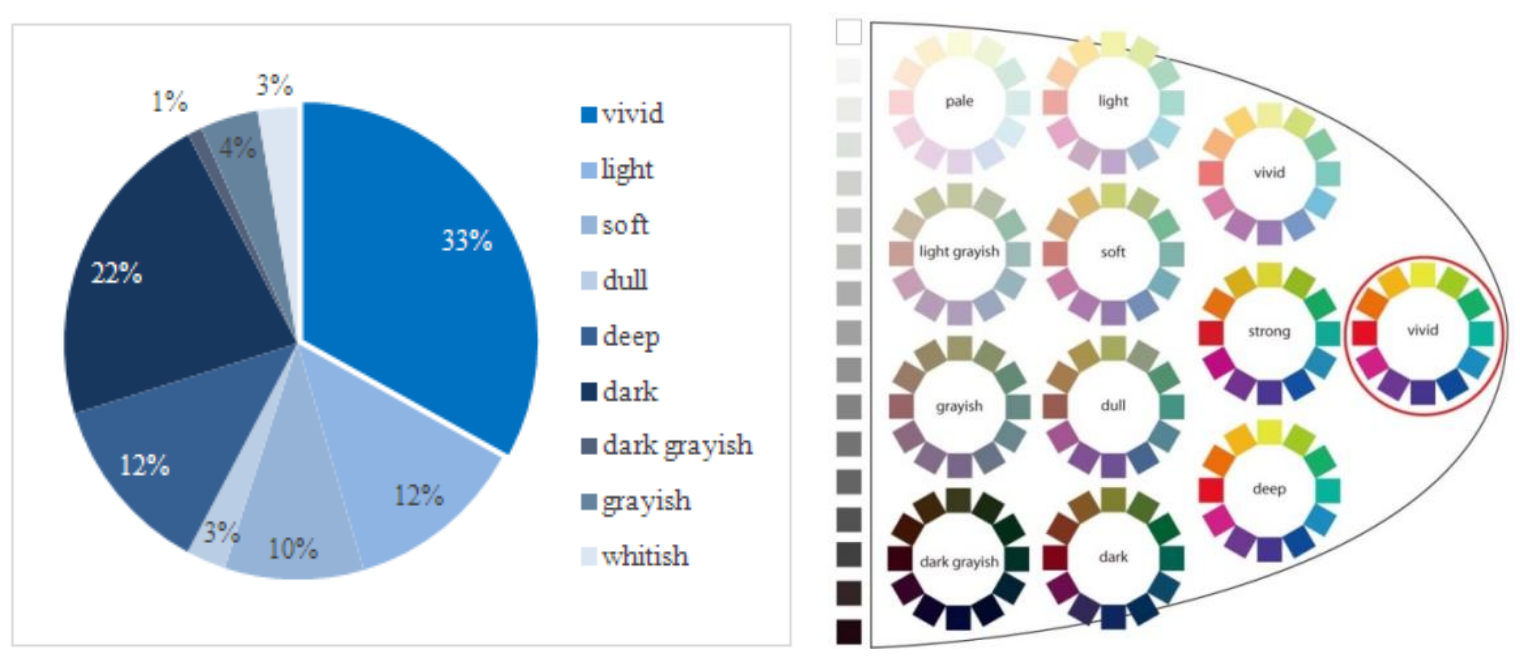

Figure 15. The result of survey on image tone at UM

A survey of the image of the university slogan "Ilmu Puncha Kemajuan" 22 showed that "Knowledge" was the highest identity at $30 \%$, indicating a strong academic image. Characteristics like "Classic" and "Education" were also high at 20\%, showing a strong image of traditional focus of science and education.

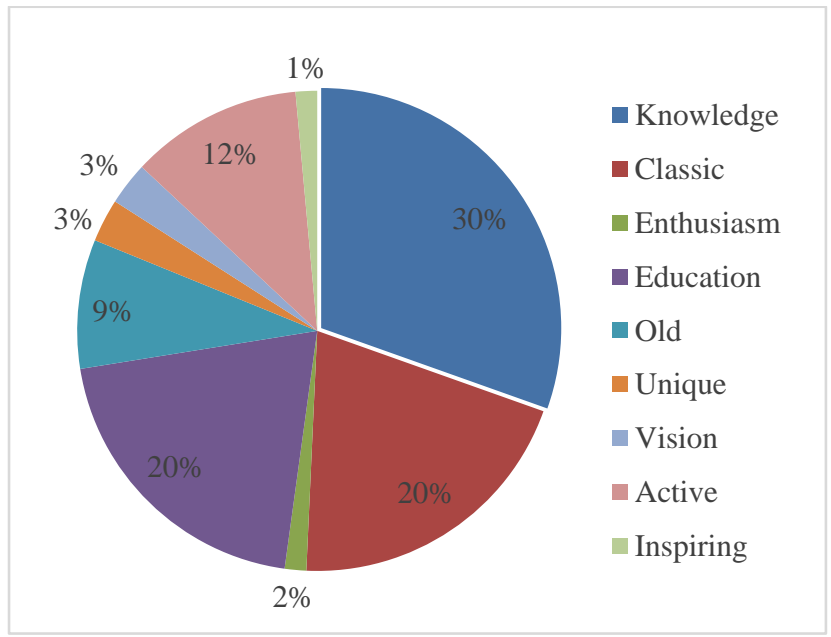

Figure 16. The result of survey on image of UM's motto

22 University Malaya webpage, Warta Universiti, https://www.um.edu.my/docs/warta-universiti/warta-um2018.pdf?sfvrsn=2 accessed at 1 December 2019. 


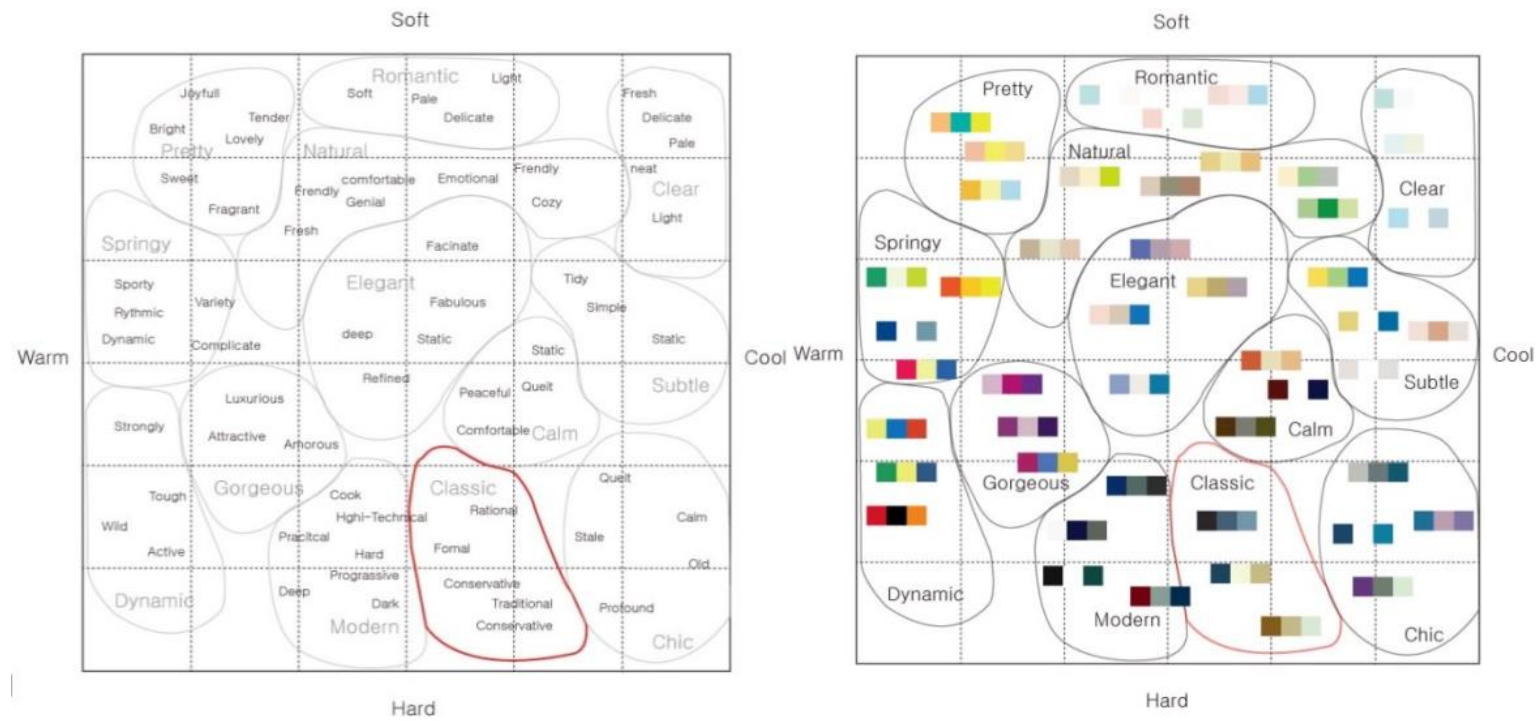

Figure 17. IRI image scale on image of UM motto

Figure 18 shows the colours and tones of UM's academic target image are associated with "yellow" as the most used colour at 55\%. "Blue" and "purple" were the next highest, at $20 \%$ and $9 \%$, respectively. In terms of tones, the highest is at $55 \%$ of lighter tones, followed by "vivid" ones with $43 \%$. Tone usage indicates that it is clear and precise without any lower variations in the targeted image (Figure 19).

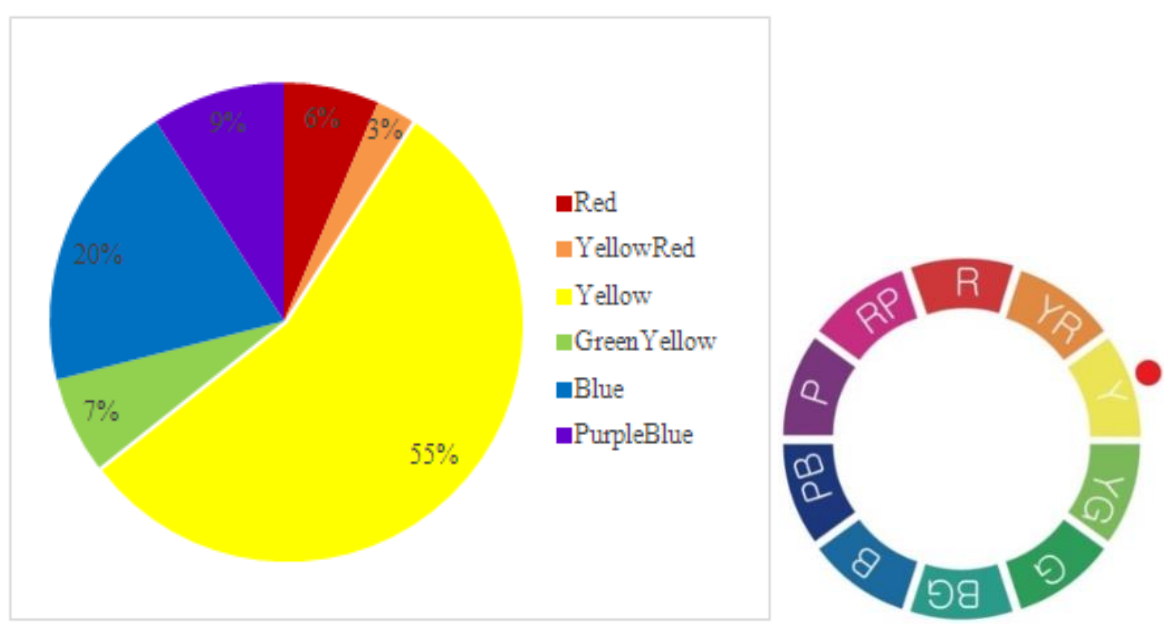

Figure 18. The result of survey on image colour of UM motto 


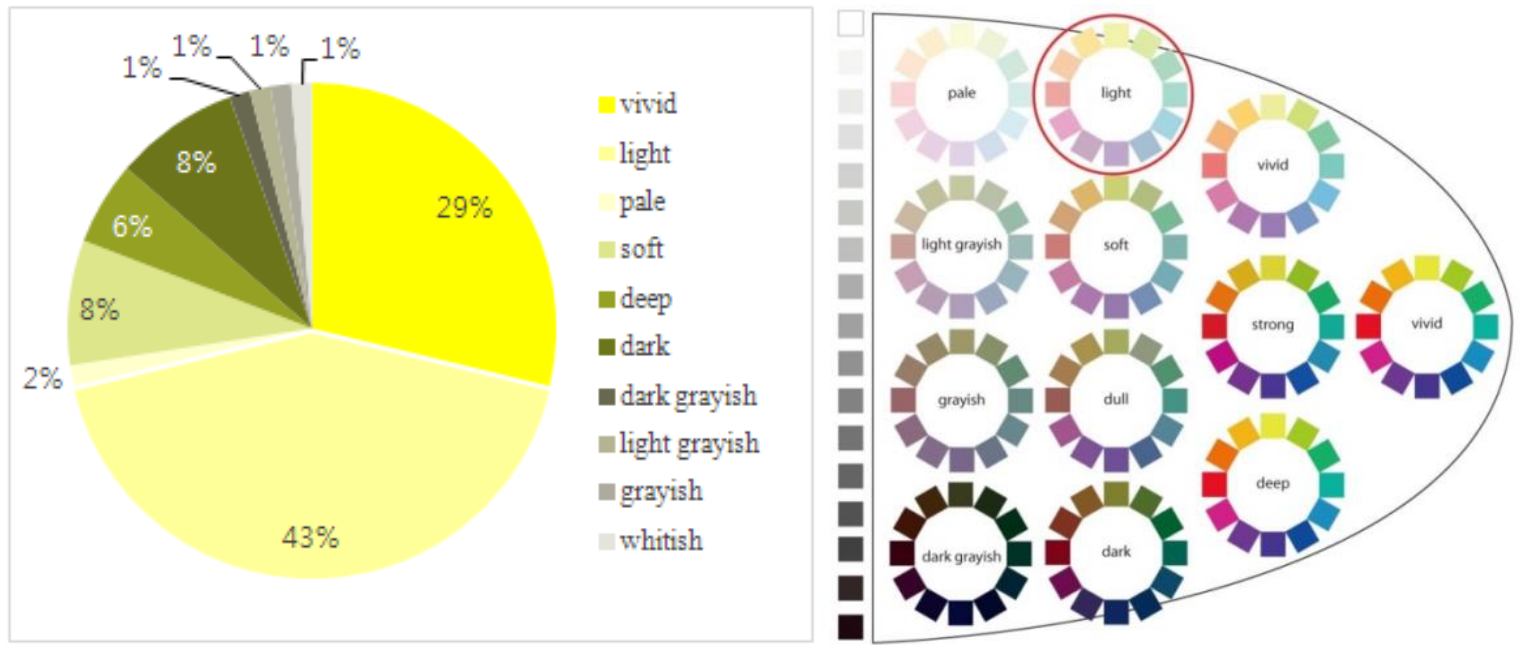

Figure 19. The result of survey on tone image of UM's motto

\section{Guidelines and composition of colour palette for UM}

This study proposes the usage of "primary colour "sub colour," and "second colour" as UM's colour palette by analyzing the elements of human environments, physical images, exclusivity, natural environments, association images, and motto. The primary colour is extracted from the three colours used in the UI of UM, expressed in blue, yellow, and red colours in CMYK, RGB, and Pantone colours (Figure 20).

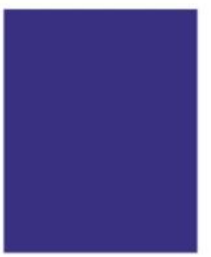

MALAYA BIUe CMYK : 949660 RGB : 5949131 PANTONE 2736C

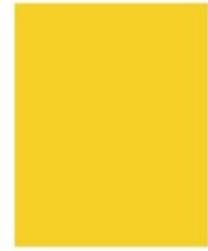

MALAYA Yellow

$C: 6 \mathrm{M}: 15 \mathrm{Y}: 88 \mathrm{~K}: 0$ RGB : 24520940 PANTONE Midieum Yellow

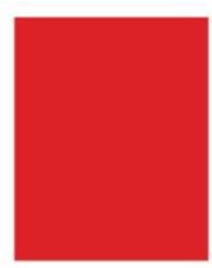

MALAYA Red

C : $6 \mathrm{M}: 96 \mathrm{Y}: 88 \mathrm{~K}: 0$

RGB : 2193438

PANTONE 2035C

Figure 20 . Primary colours of UM

The sub colour is proposed as a colour that is not high in saturation, which can serve as an auxiliary colour by to analyze the natural environment and human-environment elements of UM (Figure 21). 


\begin{tabular}{|lllll}
\hline CMYK & 37574229 & & CMYK & 53347719 \\
\hline RGB & 13898102 & RGB & 12212874 \\
\hline CMYK & 29524722 & CMYK & 68402710 \\
RGB & 162116197 & RGB & 89124149 \\
\hline CMYK & 38424727 & CMYK & 64383113 \\
\hline RGB & 140121109 & RGB & 96126143 \\
\hline CMYK & 36515537 & CMYK & 2316281 \\
\hline RGB & 1299882 & RGB & 203202185 \\
\hline CMYK & 41635856 & CMYK & 3521293 \\
\hline RGB & 966357 & RGB & 174182176 \\
\hline CMYK & 33474927 & CMYK & 8170 \\
\hline RGB & 147115101 & RGB & 238245241 \\
\hline CMYK & 29526025 & CMYK & 129210 \\
\hline RGB & 15711187 & RGB & 230225206 \\
\hline CMYK & 56405129 & CMYK & 2525456 \\
\hline RGB & 106111101 & RGB & 193177142 \\
\hline CMYK & 66369226 & 901149 & CMYK & 36303911 \\
\hline RGB & 96252156142 \\
\hline
\end{tabular}

Figure 21. Colours proposed as sub colour of UM (18 kinds)

The second range of colour was then suggested as a colour that was able to act as an accent colour with high saturation in the academic background and elements of the humanities environment (Figure 22).

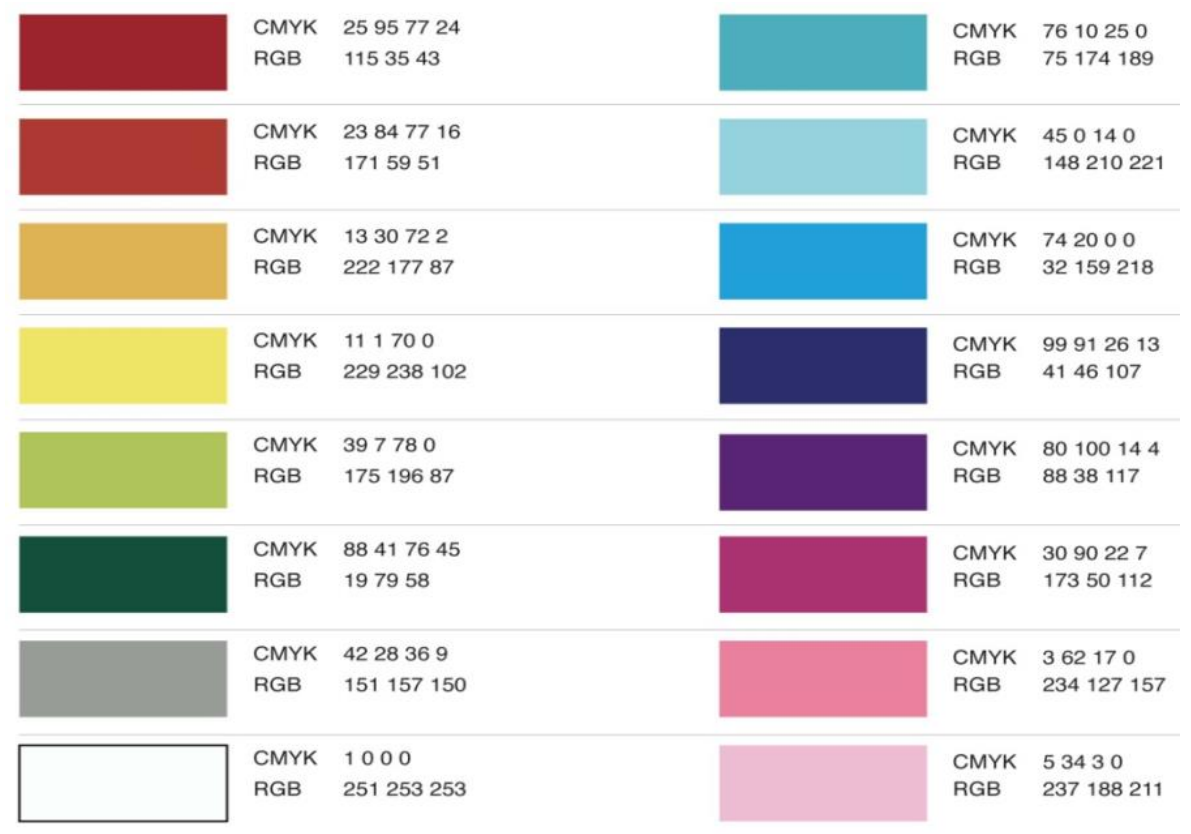

Figure 22. Proposed second colours of UM (18 types) 
Using the colours of the UM colour guidelines as proposed; this research applied colours to signboards in various spaces in campus by increasing their explicitness and readability.

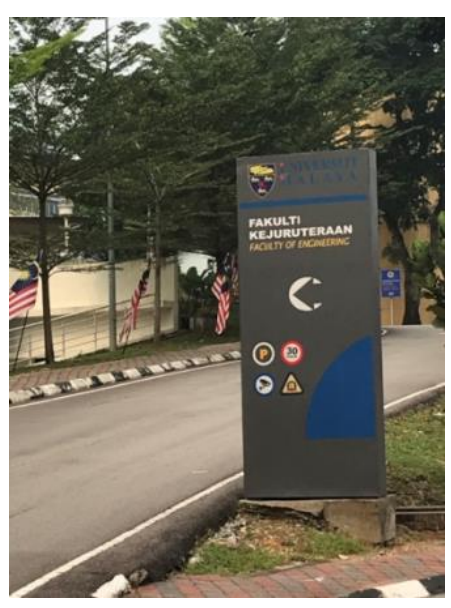

(A)

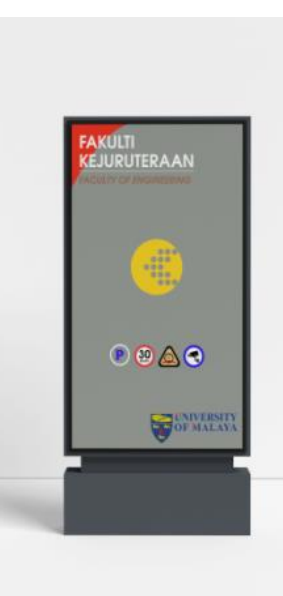

(B)

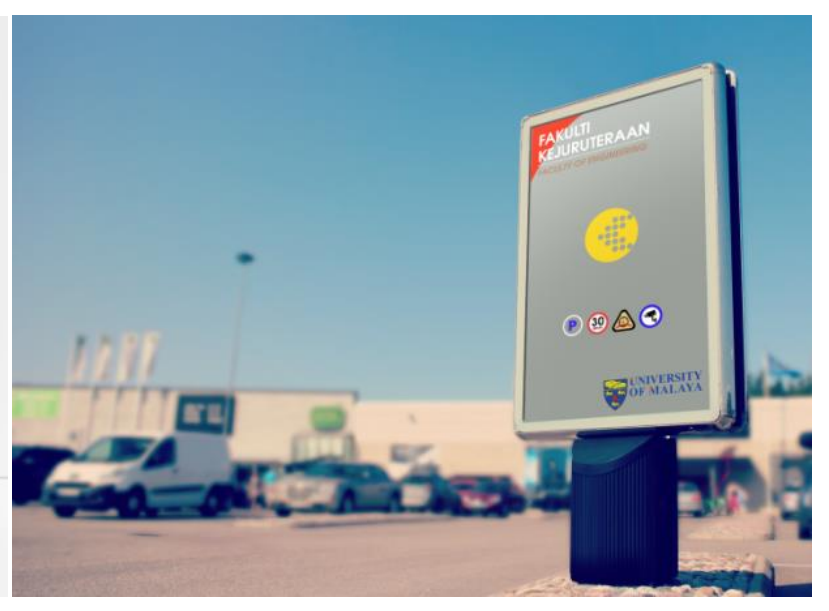

(C)

Figure 23. Signboards in UM (A: signboard in present, B, C: newly designed signboards suggested by colour guidelines)

\section{Conclusion}

The purpose of this study is to propose how colour guidelines that can be used in universities to construct a colour palette to enhance the competitiveness and strengthen the identity of the university. The subject of the analysis was University of Malaya (UM), a national university located in Kuala Lumpur, Malaysia.

The scope of research included physical images such as main colours and natural environments around UM along with human environmental elements.In terms of research methodology, pictures were taken with the Adobe Illustrator Eyedropper tool and Canon EOS M3 mirrorless camera; they were colour-coded into the Munsell system using visual inspection and digital mosaic. They were then extracted using questionnaires to realize additional images and colours of humanities and environmental elements.

Hence, the final suggestions of colour guidelines for UM are as follows. Primary colours were proposed by extracting the colour of the exclusive colours used in the UI of UM; and sub colours were recommended based on the questionnaire results and the colours extracted from the nature and humanities environments. Second colour or point colour was 
conjured by high saturation colour, which is the colour of UM's graduation gown and other academic backgrounds in the survey results. All colours have been suggested will embody the environmental elements of the university not only in colour but also as the colour of association, symbol, and space.

In addition, various colour plaettes have been proposed beyond the limitations of the existing monotonous tone changes. In other words, the recommended colours can be used for UI or layout design series or variations, and be applied in many other fields. It is expected that this study will be a meaningful case study in that it has created colour guidelines for UM designed to be utilized in channels and format that are accessed by many. In so doing, the authors believe that colours proposed here will be able to evoke a newer identity corresponding with UM's identity and status.

\section{REFERENCES}

Bae, uri, "A Study on coloration of brand logo design focusing on Top 100 of most valuable global brands in 2015" , Milward Brown, in unpublished Ph.D.dissertation, Hongik University, 2016.

Chun, Semi and Son, Won-jun, 'A study on Colour identity for formation of company's image,' Journal of Korea Design Forum, Vol. 47, 2015

Jeong Jin-sook, 'A study on materialization of web identity for a design of University's website,' Journal of Korea Design Forum, Vol. 12, 2005.

Kim, Hyun-Sun, 'A Study on extraction local character from Seoul, Korea Society of Color Studies,' Vol. 24, No. 4, 2010.

Kim Min-ki, Kim Yu-sun, Lee Ki-young, The official guide for Industrial engineers of Colorists, Seoul: Mijinsa, 2018.

Kwon, Yoon-Kyung, 'Correlation between slogan design and symbol mark of UI in University,' Korean Contents Association, Vol. 13, No.8, 2013.

Lee, Ha-na, 'A study on logo design for enhancing competitiveness of college's brand focusing on color and pattern of University of Art and Design's logo affiliated in AICAD, USA,' A Journal of Brand Design Association of Korea, Vol. 16, No.3, 2018.

Park Yeon-sun, A dictionary for terms in fields of color design, Seoul: Yeorim, 2007.

Son, Hye-yeon, 'A study on color design of sign and homage based on University's UI focusing on universities in Cheon-an', Journal of Korean Society of Colour Studies, Vol. 2, No. 3, 2009.

Seoul Metropolitan Government, Introduction of Seoul's symbol-color, http://www.seoul.go.kr/seoul/color.do?tr_code=short, accessed 26 Feb 2020.

$\mathrm{Yu}$, In-ha and Ji, Won-bae, 'An analysis on color and pattern of University's Symbol mark design in terms of UI (University Identity) focusing on Universities in Seoul', Journal of Communication Design, Vol. 40, 2012.

Weeber, Joy, E., Ronald L. Mace, https://www.britannica.com/biography/Ronald-L-Mace, date unavailable, accessed at 1 December 2019. 